De \#29273

DA:NA

$0+123 / 2001$

MOL . 20010913.0198

\title{
Spent Fuel Criticality Benchmark Experiments
}

Prepared by John M. Scaglione

Bechtel SAIC Company, LLC

July 21, 2001

Submitted to the

American Nuclear Society

ANS 2001 Winter Meeting and Embedded Topical Meetings,

November 11-15, 2001,

Reno, NV

Acknowledgement:

The Yucca Mountain Site Characterization Office as part of the Civilian Radioactive Waste Management Program supported the work for this paper. This project is managed by the U.S. Department of Energy (DOE), Yucca Mountain Site Characterization Office. The technical work was funded under DOE Contract Number

DE-AC08-01RW12101 


\title{
Spent Fuel Criticality Benchmark Experiments
}

\author{
John M. Scaglione \\ Bechtel SAIC Company, LLC \\ 1180 Town Center Drive \\ MS 420 \\ Las Vegas, NV 89144 \\ Telephone: (702) 295-4485 \\ FAX: (702) 295-4438 \\ Email: John_Scaglione@ymp.gov
}

\begin{abstract}
SUMMARY
Characteristics between commercial spent fuel waste packages (WP), Laboratory Critical Experiments (LCEs), and commercial reactor critical (CRC) evaluations are compared in this work. Emphasis is placed upon comparisons of $\mathrm{CRC}$ benchmark results and the relative neutron flux spectra in each system. Benchmark evaluations were performed for four different pressurized water reactors using four different sets of isotopes. As expected, as the number of fission products used to represent the burned fuel inventory approached reality, the closer to unity $\mathrm{k}_{\text {eff }}$ became. Examination of material and geometry characteristics indicate several fundamental similarities between the WP and CRC systems. In addition, spectral evaluations were performed on a representative pressurized water reactor CRC, a 21-assembly area of the core modeled in a potential WP configuration, and three LCEs considered applicable benchmarks for storage packages. Fission and absorption reaction spectra as well as relative neutron flux spectra are generated and compared for each system. The energy dependent reaction rates are the product of the neutron flux spectrum and the energy dependent total macroscopic cross section. With constant source distribution functions, and the total macroscopic cross sections for the fuel region in the CRCs and WP being composed of nearly the same isotopics, the resulting relative flux spectra in the CRCs and WP are very nearly the same. Differences in the relative neutron flux spectra between WPs and CRCs are evident in the thermal energy range as expected. However, the relative energy distribution of the absorption, fission, and scattering reaction rates in both the CRCs and the WP are essentially the same.
\end{abstract}




\section{INTRODUCTION}

Historically, benchmark experiments have been performed in the laboratory representing the configuration and materials of interest requiring a safety evaluation - laboratory critical experiments (LCEs). These experiments typically are performed under the assumption that the fuel is unirradiated in order to bound the configuration for criticality safety. With regard to spent nuclear fuel (SNF) disposal and transportation, significant financial benefits provide an incentive to seek burnup credit (credit for the reduction in reactivity due to fuel burnup) for criticality safety evaluations. For applications where credit for fuel burnup will be used, spent fuel benchmark experiments are necessary.

Commercial nuclear power plants and fuel vendors have demonstrated the ability to predict core burnup behavior with computer simulations through successful fuel reload licensing. These simulations are based on measured data from the power plant during reactor operation, and used to develop core reload configurations and fuel management plans. This information from the reactor operating history provides numerous critical experiment data related to burned fuel. Reactor startups at the point of initial criticality can be considered critical experiments and are identified as commercial reactor criticals (CRCs). These CRCs represent an integral approach (depletion and criticality) to calculating the effective multiplication factor $\left(k_{\text {eff }}\right)$ for the reactor of interest.

This paper demonstrates the suitability of CRCs as spent fuel criticality benchmark experiments and demonstrates the applicability for a potential storage package design. It illustrates CRC benchmark results, provides comparisons of neutron spectrum for CRCs, LCEs, and a storage/waste package (WP) design, and the effects on reaction rates arising from differences between each system.

\section{DESCRIPTION OF WORK}

A CRC statepoint is defined as a specific point in the operation of a commercial power reactor when the reactor is critical $\left(\mathrm{k}_{\mathrm{eff}}=1\right)$, not producing power (hot zero-power), and had enough down time prior to startup for the Xe-135 to decay away. The operational history of the reactor is followed with various measurements of the reactor core conditions. Therefore, a CRC is very similar to an LCE in that the geometry and conditions affecting criticality are directly measurable. The primary difference is that LCEs typically use fresh fuel material with known isotopic content, where the CRC uses depleted fuel. In order to determine the isotopic composition of the depleted fuel assemblies in the CRC, the reactor core follow data (measured over the course of operation) is used in a depletion code. This method of using core follow data to predict the isotopic inventory of depleted fuel is used throughout the commercial industry for fuel reload analyses. The varied operating conditions that each fuel assembly experiences prior to the statepoint are modeled and the resulting isotopics are used in a reactivity code to determine the $\mathrm{k}_{\mathrm{eff}}$ of the system.

As stated in the ANSI/ANS 8.1 standard, "Bias shall be established by correlating the results of critical and exponential experiments with results obtained for these same systems by the 
calculational method being validated". The bias value, that is representative of a code system's (code $\&$ data) ability to accurately predict the $\mathrm{k}_{\text {eff }}$ for a configuration, must be derived from benchmark evaluations that have neutronic characteristics that have been shown to be applicable to those configurations to which the bias value will be applied. Guidelines for experiment selection come from Lichtenwalter (1997) [1]. It states, "There are three fundamental parameters that should be considered in the selection of suitable experiments for use in the evaluation of transportation and storage package designs. They are as follows: (1) geometry of construction, (2) materials of construction (including fissionable material), and (3) the inherent neutron energy spectrum affecting the fissionable material".

With these fundamental parameters in mind, CRCs fulfill each to a degree. The geometry of the WP configuration and the CRC configuration are similar. Both approximate cylindrical systems, and the fuel assembly geometric arrangement is identical when it comes down to lattice, pin pitch, structural materials, cladding, and guide tube positions. Differences arise in the assembly-to-assembly pitch, interstitial materials between assemblies, and moderator and fuel cross-section temperature differences. Also, due to the size differences between a reactor pressure vessel and a WP, a CRC has less leakage than in a WP.

The fuel assembly material compositions used in the CRC representations are sufficiently similar to the fuel assemblies used in the WP representations. Both systems contain burned fuel isotopics. Due to the WP being designed to remain subcritical, the materials between assemblies (i.e., borated steel plates in WP) are different between the WP and the CRC. These materials cause a reduction in the multiplication factor for the WP environment.

The reflector and moderator materials are similar for both the CRC and the WP. PWR CRCs contain borated moderator which is used for additional neutron population control. The moderator to fuel ratio is greater in the WP due to the presence of full density water. The temperature in the CRC environment is greater than that in the WP environment, which has an effect on Doppler broadening of the resonances and an increase in resonance absorption. Doppler broadening refers to a change in cross section resulting from thermal motion of nuclei in a target material. The end result of these minor differences in the moderator and reflector material compositions produces a small difference in the $\mathrm{H} / \mathrm{X}$ ratio between the two systems, and causes a slight spectral shift.

SNF depleted isotopic inventories were calculated using the SAS2H control module of the SCALE [2] code package based on reactor operating history data from 4 different pressurized water reactors - Three Mile Island Unit 1 (TMI1), Crystal River Unit 3 (CR3), Sequoyah Unit 2 (SQ2), and McGuire Unit 1 (MG1). Four different sets of burned fuel isotopes were modeled for each of the CRC statepoints - best-estimate (consisting of 84 isotopes; Principal Isotopes (consisting of 29 "most important with respect to reactivity" fission products and actinides); Principal Actinides (consisting of 14 isotopes from $\mathrm{U}, \mathrm{Pu}$, and $\mathrm{Am}$ ); and Actinide Only (consisting of 10 major actinide elements found in spent fuel). The isotope sets used are presented in Table 1. 
Table 1. Fuel Isotopes Set Description

\begin{tabular}{|c|c|c|c|c|c|c|c|}
\hline Isotope & Set $^{1}$ & Isotope & Set $^{1}$ & Isotope & Set $^{1}$ & Isotope & Set $^{1}$ \\
\hline $\mathrm{H}-3$ & $\overline{\mathrm{BE}}$ & $\mathrm{Pd}-108$ & $\mathrm{BE}$ & $\mathrm{Eu}-152$ & $\mathrm{BE}$ & $\mathrm{Np}-238$ & $\mathrm{BE}$ \\
\hline $\mathrm{He}-4$ & $\mathrm{BE}$ & $\mathrm{Ag}-107$ & $\mathrm{BE}$ & Eu-153 & $\mathrm{BE}, \mathrm{PI}$ & $\mathrm{Pu}-237$ & $\mathrm{BE}$ \\
\hline Li-6 & $\mathrm{BE}$ & Ag-109 & BE, PI & Eu-154 & $\mathrm{BE}$ & Pu-238 & $\begin{array}{l}\text { BE, PI, } \\
\text { PA, AO }\end{array}$ \\
\hline Li-7 & BE & Xe-131 & $\overline{B E}$ & Eu-155 & $\mathrm{BE}$ & Pu-239 & $\begin{array}{l}\text { BE, PI, } \\
\text { PA, AO }\end{array}$ \\
\hline Be-9 & $\mathrm{BE}$ & Xe-134 & $\overline{\mathrm{BE}}$ & Gd-152 & $\overline{\mathrm{BE}}$ & Pu-240 & $\begin{array}{l}\text { BE, PI, } \\
\text { PA, AO }\end{array}$ \\
\hline $0-16$ & $\begin{array}{l}\text { BE, PI, } \\
\text { PA, AO }\end{array}$ & Cs-135 & $\overline{\mathrm{BE}}$ & Gd-154 & $\overline{B E}$ & $\mathrm{Pu}-241$ & $\begin{array}{l}\text { BE, PI, } \\
\text { PA, AO }\end{array}$ \\
\hline As-75 & $\mathrm{BE}$ & $\mathrm{Ba}-138$ & $\overline{\mathrm{BE}}$ & Gd-155 & $\overline{B E}, \mathrm{PI}$ & $\mathrm{Pu}-242$ & $\begin{array}{l}\text { BE, PI, } \\
\text { PA, AO }\end{array}$ \\
\hline $\mathrm{Kr}-80$ & $\mathrm{BE}$ & Pr-141 & $\overline{B E}$ & Gd-156 & $\mathrm{BE}$ & Am-241 & $\begin{array}{l}\mathrm{BE}, \mathrm{PI} \\
\mathrm{PA}, \mathrm{AO}\end{array}$ \\
\hline $\mathrm{Kr}-82$ & $\mathrm{BE}$ & Nd-143 & $\mathrm{BE}, \mathrm{PI}$ & Gd-157 & $\overline{B E}$ & Am-242 & $\mathrm{BE}, \mathrm{PI}, \mathrm{PA}$ \\
\hline $\mathrm{Kr}-83$ & $\overline{\mathrm{BE}}$ & Nd-145 & BE, PI & Gd-158 & $\mathrm{BE}$ & Am-243 & $\mathrm{BE}, \mathrm{PI}, \overline{\mathrm{PA}}$ \\
\hline $\mathrm{Kr}-84$ & $\mathrm{BE}$ & Nd-147 & $\mathrm{BE}$ & Gd-160 & $\mathrm{BE}$ & $\mathrm{Cm}-242$ & $\mathrm{BE}$ \\
\hline $\mathrm{Kr}-86$ & $\mathrm{BE}$ & $\mathrm{Nd}-148$ & $\overline{B E}$ & $\mathrm{~Pa}-233$ & $\mathrm{BE}$ & $\mathrm{Cm}-243$ & $\mathrm{BE}$ \\
\hline Y-89 & $\overline{B E}$ & Pm-147 & $\overline{\mathrm{BE}}$ & U-233 & $\mathrm{BE}, \mathrm{PI}, \mathrm{PA}$ & $\mathrm{Cm}-244$ & $\overline{B E}$ \\
\hline Zr-93 & $\mathrm{BE}$ & $\mathrm{Pm}-148$ & $\mathrm{BE}$ & U-234 & $\begin{array}{l}\text { BE, PI, } \\
\text { PA, AO }\end{array}$ & $\mathrm{Cm}-245$ & $\overline{B E}$ \\
\hline Nb-93 & $\overline{\mathrm{BE}}$ & Pm-149 & $\overline{\mathrm{BE}}$ & U-235 & $\begin{array}{l}\text { BE, PI, } \\
\text { PA, AO }\end{array}$ & $\mathrm{Cm}-246$ & $\overline{\mathrm{BE}}$ \\
\hline Mo-95 & BE, PI & Sm-147 & BE, PI & U-236 & $\begin{array}{l}\text { BE, PI, } \\
\text { PA, AO }\end{array}$ & $\mathrm{Cm}-247$ & $\mathrm{BE}$ \\
\hline Tc-99 & $\mathrm{BE}, \mathrm{PI}$ & Sm-149 & BE, PI & U-237 & BE & $\mathrm{Cm}-248$ & $\mathrm{BE}$ \\
\hline Ru-101 & $\overline{\mathrm{BE}}, \mathrm{PI}$ & Sm-150 & BE, PI & U-238 & $\begin{array}{l}\text { BE, PI, } \\
\text { PA, AO }\end{array}$ & $\mathrm{Xe}-135$ & $\overline{B E}$ \\
\hline Ru-103 & $\mathrm{BE}$ & Sm-151 & $\mathrm{BE}, \mathrm{PI}$ & $\mathrm{Np}-235$ & $\mathrm{BE}$ & Cs-133 & $\mathrm{BE}$ \\
\hline Rh-103 & $\overline{\mathrm{BE}}, \mathrm{PI}$ & Sm-152 & BE, PI & $\mathrm{Np}-236$ & $\mathrm{BE}$ & Ho-165 & $\overline{\mathrm{BE}}$ \\
\hline Rh-105 & $\mathrm{BE}$ & Eu-151 & BE, PI & Np-237 & BE, PI, PA & Th-232 & $\mathrm{BE}$ \\
\hline Pd-105 & $\overline{B E}$ & & & & & & \\
\hline
\end{tabular}

${ }^{1} \mathrm{BE}=$ Best-Estimate; $\mathrm{PI}=$ Principal Isotope; $\mathrm{PA}=$ Principal Actinide; $\mathrm{AO}=$ Actinide Only

SAS2H is a one-dimensional depletion code that can simulate the operating history of fuel assemblies from the measured data. The measured data was used in 16 or 18 axial node format - depending on the reactor - to model the burnup of the fuel for each assembly through its unique operating history profile. The SAS2H results provide burned fuel isotopics that can be modeled as fuel compositions in MCNP [3]. MCNP is a Monte Carlo criticality code that is used to simulate the statepoint conditions for the CRC in conjunction with the SAS2H calculated spent fuel isotopics. Although, all isotopes in the MCNP cross section library were not available at hot reactor temperatures, U-235 is available at $587 \mathrm{~K}$ and so is U-238 which dominates the spent fuel inventory and resonance absorption. Temperature effects associated with the fuel cross sections selected are not part of this study and may be documented at a later 
date. Current work is in progress to quantify the effect of cross-section temperature differences on reactivity.

The CRC benchmark cases evaluated cover an initial enrichment range of $1.93 \mathrm{wt} \% \mathrm{U}-235$ to $4.167 \mathrm{wt} \% \mathrm{U}-235$, and an assembly average burnup range of 0 to $49 \mathrm{GWd} / \mathrm{mtU}$. Core average burnups range from $0 \mathrm{GWd} / \mathrm{mtU}$ for the beginning of life CRC statepoints to $33 \mathrm{GWd} / \mathrm{mtU}$. Figure 1 illustrates the $\mathrm{k}_{\text {eff }}$ values from the $\mathrm{CRC}$ benchmark results. The results indicate that as the number of spent fuel isotopes modeled increases, the closer to unity $k_{\text {eff }}$ becomes. The average $k_{\text {eff }}$ values for each of the isotope sets is presented in Table 2 .

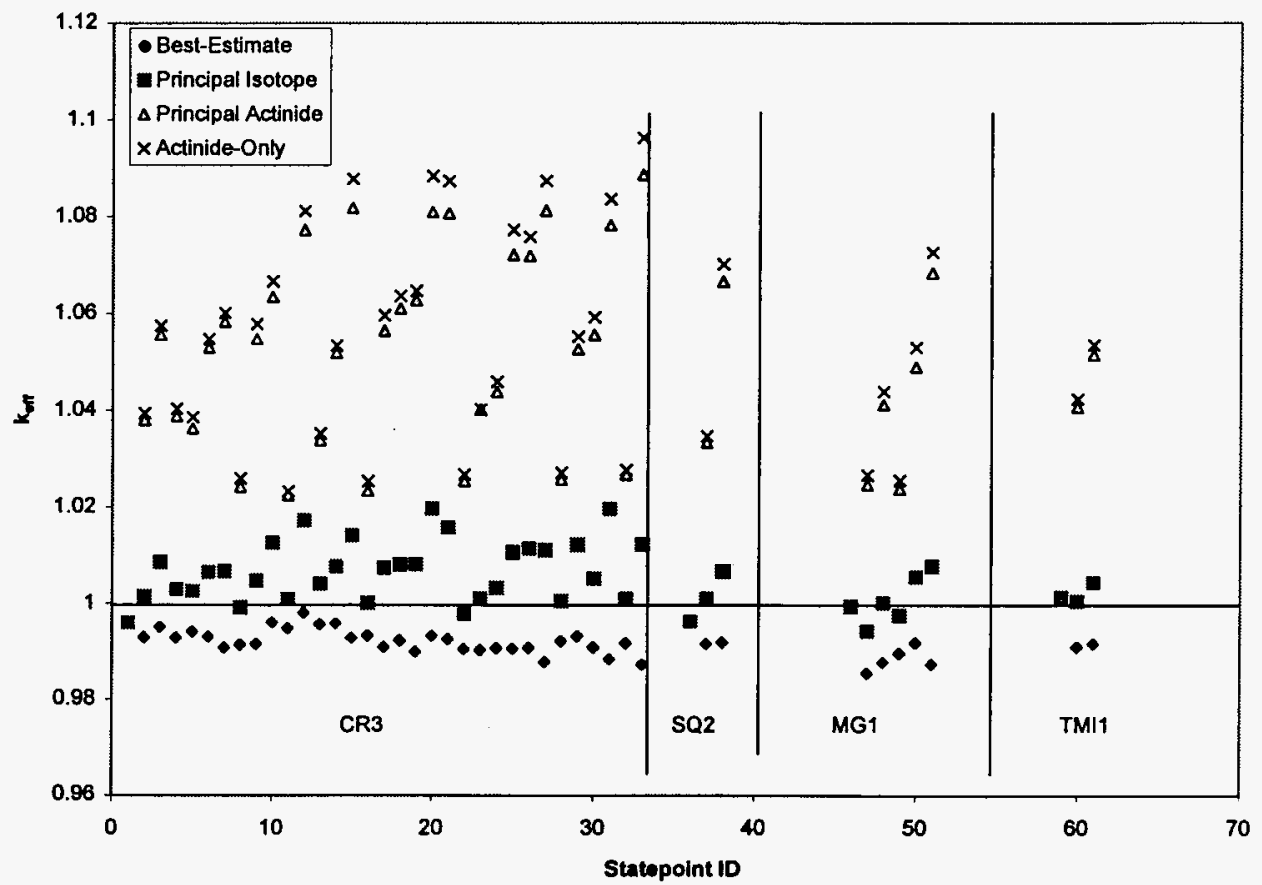

Figure 1. PWR CRC Eigenvalues [4]

Table 2. Summary of CRC $\mathbf{k}_{\text {eff }}$ Calculations

\begin{tabular}{|l|c|c|c|c|}
\hline \multirow{2}{*}{ Isotope Set } & \multicolumn{4}{|c|}{$\mathbf{k}_{\text {eff }}$} \\
\cline { 2 - 5 } & Average & Maximum & Minimum & Standard Deviation \\
\hline Best Estimate & 0.99164 & 0.99805 & 0.98541 & 0.00298 \\
\hline $\begin{array}{l}\text { Principal } \\
\text { Isotope }\end{array}$ & 1.00623 & 1.01973 & 0.99428 & 0.00291 \\
\hline $\begin{array}{l}\text { Principal } \\
\text { Actinide }\end{array}$ & 1.0516 & 1.08862 & 1.02244 & 0.00298 \\
\hline Actinide Only & 1.05454 & 1.09621 & 1.02335 & 0.00295 \\
\hline
\end{tabular}

In addition to the $\mathrm{CRC}$ benchmarks, spectral characteristics were compared for a representative 21 PWR waste package, a CRC statepoint, two MOX LCEs - Saxton53 (12x12 PuO2 lattice) and 
EPRI22 (12x12 PuO2 Lattice) - and one fresh fuel LCE (Saxton48 UO2 lattice). The neutron flux spectrum was evaluated for each system and is shown in Figure 3.

The commercial reactor used for the CRC statepoint data was the Crystal River Unit 3 PWR. This reactor uses Babcock \& Wilcox (B\&W) $15 \times 15$ fuel assemblies with 16 guide tubes. The mid-cycle restart statepoint calculation was performed 400 effective full power days (EFPDs) into Cycle 6. A fuel assembly arrangement in the CRC was modeled as shown in Figure 1. A 21-assembly area of the core was modeled in the WP as shown in Figure 1. The waste package model was loaded with a grouping of 21 assemblies out of the CRC statepoint to remove material composition differences from the comparison. The burned fuel assemblies represented in the WP varied in average assembly burnup from $16.358 \mathrm{GWd} / \mathrm{MTU}$ through $34.416 \mathrm{GWd} / \mathrm{MTU}$, and initial enrichments of 2.62 through $3.49 \mathrm{wt} \% \mathrm{U}-235$. Each of the fuel assemblies was modeled explicitly with 18 axial nodes in both the CRC and in the WP, and was depleted through each of their own unique operating history profiles.

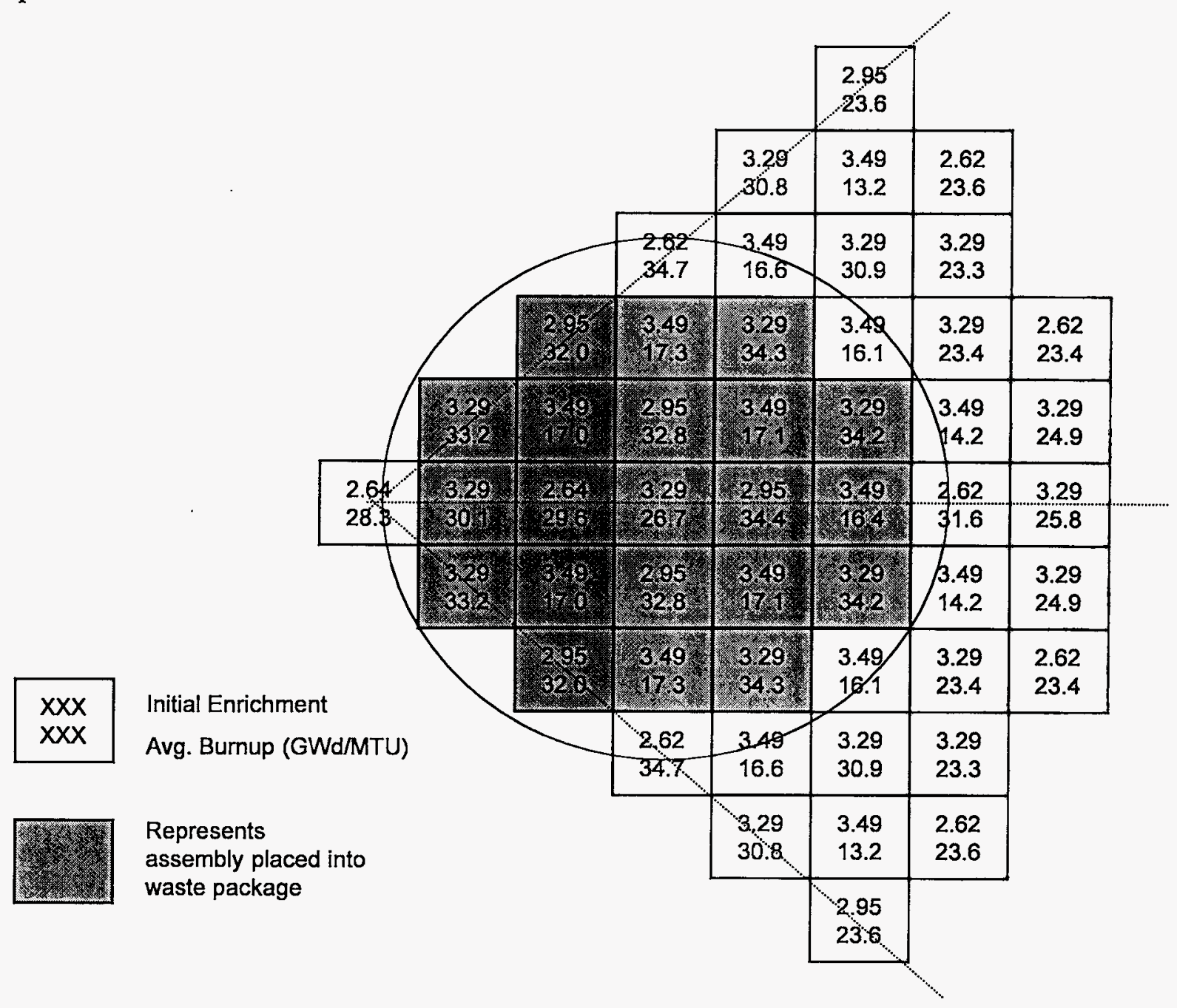

Figure 2. Burned Fuel Assembly Positioning in CRC and WP 
In a light water moderated and reflected environment with fuel rods arranged in a lattice configuration, the neutronic behavior (spectra) is expected to be fairly constant in terms of relative distribution regardless of the surrounding environment. Differences in neutron spectra between the various configurations are expected to occur as a result of factors including $\mathrm{H} / \mathrm{X}$ ratio, material differences, and moderator temperature differences.

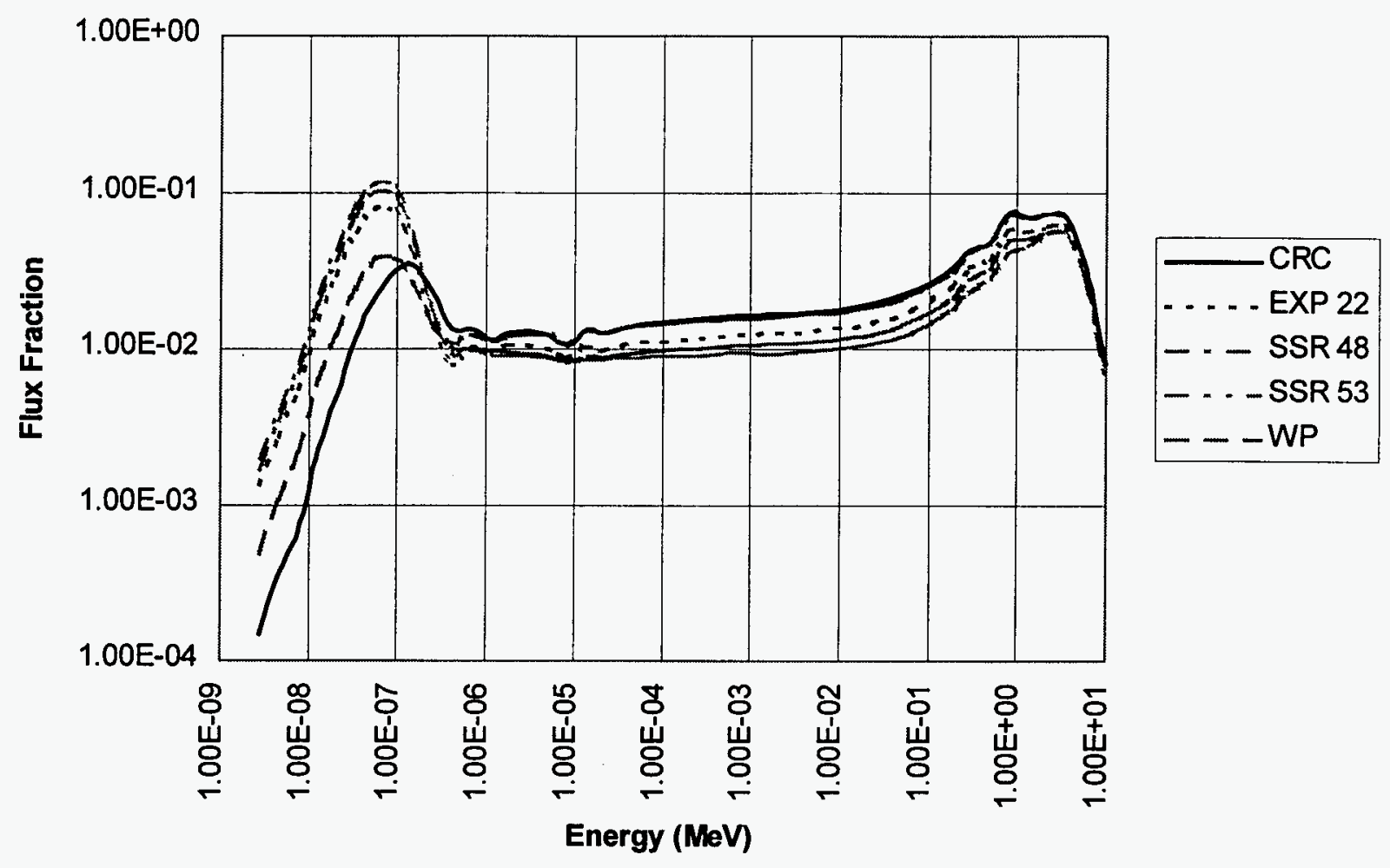

Figure 3. Neutron Energy Spectra of WP and Critical Benchmarks

A basic understanding of the effect of the spectral variations on reactivity can be made by evaluating the fission and absorption reaction rates between the systems. The energy dependent reaction rates are the product of the neutron flux spectrum and the energy dependent total macroscopic cross section. The probability of a fission reaction occurring in the fuel material when a neutron is absorbed in the fuel can be expressed in terms of cross sections. It is simply the ratio of the fission cross section to that of the absorption cross section in the fuel material. With the total macroscopic cross sections for the fuel region in the CRCs and WP being composed of nearly the same isotopics, the fission probability in the fuel material for these two systems will be very nearly the same as shown in Figure 4. A plot of reaction rate ratios for a fresh fuel WP configuration is also provided for comparison against the LCEs in order to exhibit that the fuel material composition is what is governing the reaction rates. The magnitude of the fission to absorption ratio for the CRCs and WP will vary based on burnup, but the shape and area under the curve is expected to remain the same between the two systems. 


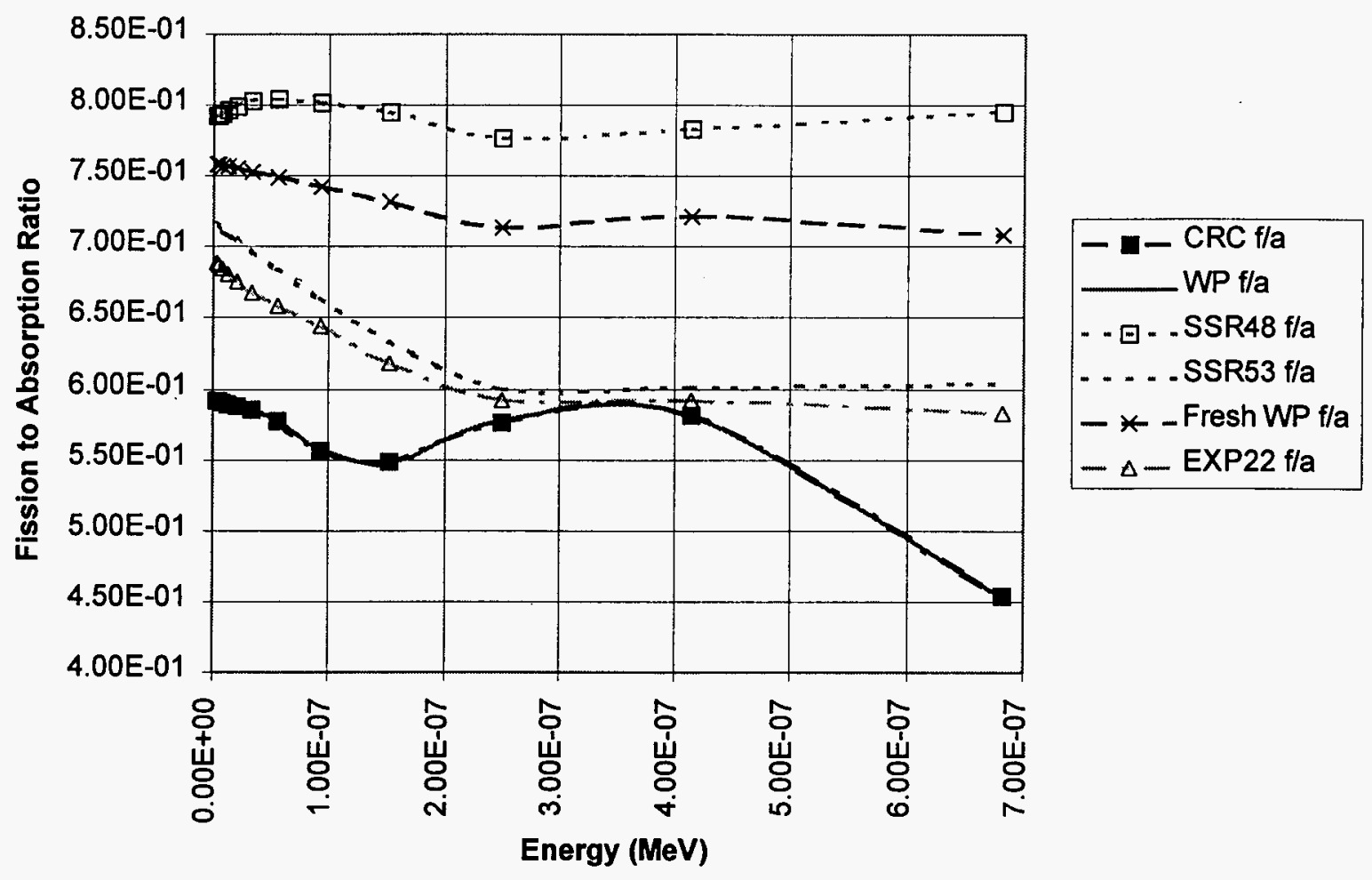

Figure 4. Thermal Region Reaction Ratio Comparison

\section{CONCLUSIONS AND RECOMMENDATIONS}

The results summarized in Figure 1 confirms that the criticality benchmarks with the set of CRCs are applicable to burned fuel criticality evaluations. In terms of applicability to a storage package design, although there are no critical experiments that match a storage package configuration containing burned fuel assemblies in all aspects, CRCs have been shown to provide an adequate method of generating burned fuel isotopics. In the spectral characteristic comparisons, the average flux fraction versus energy was calculated across the system as well as the fission and reaction rates. Although spectral shifts of the type seen in the LCEs are the result of several effects (e.g., material, $\mathrm{H} / \mathrm{X}$, etc.), when compared to the WP, the results indicate that $\mathrm{CRCs}$ are just as adequate for benchmarks and more closely represents the reaction rates for burned fuel in a storage package configuration.

When it comes to criticality safety analysis and addressing the requirements of ANSI/ANS 8.1, the establishment of the code bias can be made with the results from CRCs and LCEs together to ensure adequate safety margin for applications using burnup credit in storage packages. 


\section{REFERENCES}

1 Lichtenwalter, J.J.; Bowman, S.M.; DeHart, M.D.; and Hopper, C.M. 1997. Criticality Benchmark Guide for Light-Water-Reactor Fuel in Transportation and Storage Packages. NUREG/CR-6361. Washington, D.C.: U.S. Nuclear Regulatory Commission.

2 ORNL (Oak Ridge National Laboratory) 1997. SCALE: A Modular Code System for Performing Standardized Computer Analyses for Licensing Evaluation. NUREG/CR-0200, Rev. 5. Washington, D.C.: U.S. Nuclear Regulatory Commission.

3 Briesmeister, J.F., ed. 1997. MCNP-A General Monte Carlo N-Particle Transport Code. LA12625-M, Version 4B. Los Alamos, New Mexico: Los Alamos National Laboratory.

4 CRWMS M\&O 1998. Summary Report of Commercial Reactor Critical Analyses Performed for the Disposal Criticality Analysis Methodology. B00000000-01717-5705-00075 REV 01. Las Vegas, Nevada: CRWMS M\&O. ACC: MOL.19980825.0001. 